processes involved. Other features of the proposal involve extensive drilling into the ocean crust itself in an effort to learn more about the processes by which it was formed, and to study the evolution and environmental changes which have occurred.

The committee cautions that the programme should not be attempted at all unless there is a firm assurance of support for extensive geophysical survey work before drilling takes place, and sufficient funds to analyse and interpret the results. "An investment in a drilling vessel without a commensurate investment in scientific investigations on an appropriate scale could not be supported in good conscience", the report states.

The proposal will be sent officially to NSF in the next few weeks, and responsible programme officials will seek authority from the Director and the National Science Board to look further into the scientific merits of the plan (a task which, as one NSF official wryly observed last week, will be complicated by the fact that virtually everybody capable of offering an independent opinion participated in drafting the proposal). If the programme is deemed meritorious, NSF will eventually seek funding, first from the Office of Management and Budget and later from Congress. At some stage, it is almost certain that the matter will land on the desk of Frank Press, President Carter's science adviser, who is a distinguished geophysicist himself.

For a project of that cost and scope, international participation would be an obvious advantage. At present, non-US participants in the DSDP each contribute $\$ 1$ million a year in direct costs and a further sum in supporting the work of their own researchers in analysing and interpreting the results. NSF officials note that economic and political difficulties might mitigate against foreign participation.

The British commitment, for instance, is to support IPODI until 1978 , and a request for a further year's support is expected soon. The British package of support is complex, however, involving sums of money from three separate departments, and any request for financial commitment at this stage for a period of ten years might pose problems.

The first decade of drilling with the Glomar Challenger has provided some spectacular results and answered some fundamental problems. But it has also thrown out some intriguing questions which can be answered only with more expensive equipment which will be more costly to operate. The same pattern can be discerned in fields such as particle physics and even molecular biology. It should be no surprise that it is now happening to geophysics.

NETHERLANDS

\title{
Dutch go ahead on DNA
}

Casper Schuuring reports from the Netherlands on moves to control recombinant $D N A$ research there

RECOMBINANT DNA research should be developed in the Netherlands because of its great scientific importance, according to a report from the country's Commission on Genetic Engineering which was handed over to the Ministers of Health and for Science Policy on 3 March and published on 30 March. The research should be carried out with stringent precautions and according to clear regulations contained in legislation which, in the commission's opinion, should be implemented quickly.

The commission, which started work just one year ago, also proposes a special committee with responsibility for surveillance of the research. It would continue the work of the present commission on a legal basis, and have on it representatives of the biomedical sciences, of other related sciences (legal and ethics), of the government and of society at large. The commission, which consists only of experts in the field, also suggests another committee to consider broader ethical and social aspects of the applications of advanced medical and biological research and whether to bring such research within the framework of legislation.

The commission supports the European Science Foundation's recommendation that the rules of the British Williams report be followed, but considers that on a couple of points the report is insufficiently clear. Plans for recombinant DNA research must be reported to the 'surveillance committee', and research cannot go ahead unless a statement that there is no objection to it has been obtained and an 'examination commission' has been established to check that all requirements are fulfilled. That body has the right to do investigations on the spot.

The commission prefers the description of the four levels of physical containment of the Williams report. It says that a laboratory with the highest containment level should not be established in the Netherlands, and that experiments on that level should be done at a 'European' laboratory, but it says there is a great need for facilities with containment one level lower. Regarding levels of biological containment, the commission has opted for the rules contained in the NIH regulations in the USA. For each experiment the requirements for biological containment will be left to the surveillance committee.

The commission also prefers the NIH view that certain experiments should not be carried out at the moment. The Williams report did not exclude any experiments completely. Those prohibited include the cloning of recombinant DNA from pathogenic organisms (class 3, 4 and 5) or from oncogenic viruses; the purposeful cloning of that DNA from organisms coding for the production of toxins (botulinum, diphtheriae); the establishment of a transfer of resistance against (for example) antibiotics to microorganisms missing that natural resistance; and experiments enhancing the virulence of phytopathogenic microorganisms.

On a list of examples of experiments with non-purified DNA of organisms not secreting toxic products and the conditions under which they should be carried out, the commission separates primates from other mammals, which the Williams report did not do. Concerning prokaryotes the commission distinguishes DNA from organisms which exchange genetic information with $E$. coli and those which do not. In the commission's opinion the second category carries a higher potential risk. Finally, experiments which use nucleic acid from animal viruses not pathogenic for man have to be placed in a higher category than the Williams report suggested.

So far nine projects, one of which is already in progress, have been lodged with the commission. One has to be classified as belonging to the category of research which cannot be carried out in the Netherlands; the level of two others has not been determined, while another two are P1-level experiments and two more are P2 (according to NIH regulations). Two others are $\mathrm{P} 1$ projects.

The establishments involved so far are the University of Amsterdam (3 projects), the Free University in Amsterdam (1), the University of Leiden (3), the University of Groningen (1) and the University of Nijmegen (1). Other universities and research institutes are preparing to do recombinant DNA research. From industry only Unilever is making preparations.

The foundation 'Biosciences and Society', which gives information on a regular basis on biomedical subjects, remarked on the report in its 31 March bulletin. It says that the commission, "consisting exclusively of prominent Dutch scientists, has hardly occupied itself with the social desirability of the recombinant DNA-research". It goes on: "The report gives no answer to the critics who doubt whether this research is socially necessary. These critics say that some results can also be reached another way." 